\title{
Theoretical Study on the Conformations of Homooxacalix[4]arenes
}

\author{
Sihyun Ham \\ Department of Chemistry, Sookmytng Women's University, Seoul 140-742, Korea \\ Received October 7, 2004
}

\begin{abstract}
The conformational preference of tetrahomodioxacalix[4]arenes with three different para substituents on the phenolic ring has been investigated by using ab initio molecular orbital theory (RHF/6-3lG*) and density functional theory (B3LYP/6-3 $\mathrm{IG}$ ). The stability order is predicted to be cone $>\mathrm{C}-1.2$-alternate $>$ partial cone $>1.3$-alternate $>$ COC-1.2-alternate. The distorted cone conformation is found to be most stable in a gas phase and the calculated results are in agreement with the reported ${ }^{1} \mathrm{H}$ NMR and X-ray experimental observations. The substitution of methylene with dimethyleneoxa bridges increases the size of the anmulus of the molecule. its conformational mobility, and the number of hydrogen bonding pattems. The thennodynamic stability and the confonnational characteristics of tetrahomodioxacalix[4]arenes are discussed in regards of the number of phenolic hydrogen bonding patterns and the polarity of a molecule. The substituent effects on the para position of the phenolic ring are also introduced.
\end{abstract}

Key Words : Calix[4]arenes. RHF/6-31G*, Conformation, Stability order, Hydrogen bond

\section{Introduction}

Calixarene chenistry has been explored with great attention due to its potential accessibility for molecular recognition. ion transport phenomena. enzyme model building. and the construction of sensors for a wide variety of applications. ${ }^{1}$ Homooxacalixarene, where $-\mathrm{OCH}_{2}$ - groups are incorporated into the calixarene macrocycle are useful platform for the design of molecular containers with different cavity size and conformational flexibility. ${ }^{2-7}$ Tetrahomodioxacalix[4]arene (1-3 in scheme 1), containing two extra oxygen atoms in the macrocyclic ring. can provide larger cavity. greater flexibility. and extra coordination sites for guest complexation compared to calix[4]arene. ${ }^{8-19}$ However due to the synthetic difficulties. only limited studies have been reported on the syntheses. conformational analyses. and complexation of tetrahomodioxacalix[ 4 ]arenes. The first cry'stal structure of tetrahomodioxa $p$-t-butylcalix[4]arene was reported by Thuery et $a f$ to be a very distorted cone conformation containing intramolecular hydrogen bonding array which links both phenolic and ether groups. ${ }^{11.12}$ No et al. described the new designation with appropriate nomenclature on the five different confonnations of

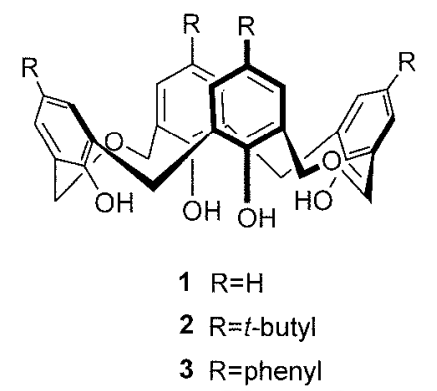

Scheme 1. Structure of tetrahomodioxacalix[4]arenes denvatives.

e-mail: silhyungọsookmyung.ackr tetrahomodioxacalix[4]arene to be cone. partial cone. C-1.2alternate. COC-1.2-alternate and 1.3-alternate as indicated in Figure $1{ }^{1:}$ Recently, tetrahomodioxacalix [4]arene derivatives have been synthesized and several experimental attempts have been made to determine the conformational preference depending on the substituents. ${ }^{1+2 !}$ Yet. no theoretical studies on the confomational preference of the homooxacalix[4] arenes have been reported. Since conformational mobility is detrimental to guest binding/inclusion. a mandatory step for the design of effective homooxacalix[4]arenes-based receptors is to understand the nature and origin of the conformational stability of parent homooxacalix[4]arenes. In this report, we report the first theoretical investigation on the conformations of tetrahomodioxacalix[4]arenes with three different $\mathrm{R}$ substituents. $\mathrm{R}=\mathrm{H}$. $t$-butyl, and phenyl (1-3). on the para position of the phenolic ring using semi-empirical and quantum mechanical theory: The purpose of this work is three fold. First. it is to determine the most stable

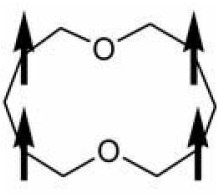

cone

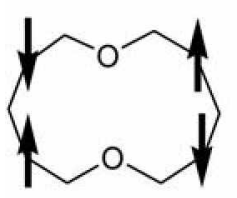

1,3-alternate

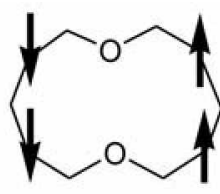

C-1,2-alternate

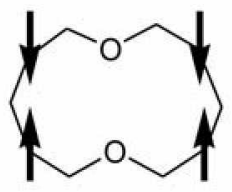

COC-1,2-alternate

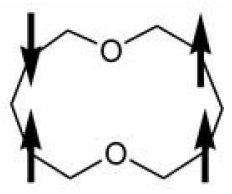

partial cone
Figure 1. Schematic representation of the tive contomations of homooxacalis[4]arenes. 
conformation of parent tetrahomodioxacalix[4]arenes in a gas phase by various computational methods and to compare the results with the available experimental data. Secondly' it is to provide the theoretical understanding on the thermodynamic stability for 1 . which can be applied to understand and predict the complexation behavior of 1 . Lastly, the result of this work can be used to design other useful homooxacalix[4]arenes-based macrocycles with various diameters. depths. and polarity:

\section{Computational Methods}

An initial conformational analysis of tetrahomodioxacalix [4]arenes was first performed by molecular dynamic (MD) simulation. The constant-temperature MD simulations were executed by using the SANDER module of AMBER program package employing parm99 force field. ${ }^{21}$ The molecular system was subject to 1000 steps of conjugate gradient energy minimization. and then brought into an equilibrium state for $100 \mathrm{ps}$ using the Berendsen coupling algorithm.: In all calculations. an $8.0 \mathrm{~A}$ non-bonded interaction cut-off was used and non-boned pair lists were updated every 20 integration steps. A 2 fs time step was used for the simulation. The simulation was performed for $300 \mathrm{ps}$ at $900 \mathrm{~K}$ and the structures were saved every $1 \mathrm{ps}$ for analyses. Thus total 300 structures were collected throughout a trajectory. Then we performed the geometry optimizations for those 300 structures using AMl semi-empirical method ${ }^{33}$ to find the energy minima that would be used as initial structures for a high-level geometry optimization. Using this method. we collected energy minima structures for each conformation and those structures were then confirmed by the vibrational frequency analysis at the AM1. For those structures. we then performed the high-level quantum mechanical calculations. The molecular orbital calculations were carried out using Gaussian 98 package. ${ }^{-4}$ Geometry optimizations were performed at the RHF/6-31G* level and a single point energy calculation was executed at the B3LYP/6$31 \mathrm{G}^{*}$ level" ${ }^{25}$ for all $\mathrm{RHF} / 6-31 \mathrm{G}^{*}$ energy minima confomations. Frequency calculations were performed to verify the identity of each stationary point as a minimum. All energies discussed in the paper are at the $\mathrm{B} 3 \mathrm{LYP} / 6-31 \mathrm{G} * / \mathrm{RHF} / 6-$ $31 \mathrm{G}^{*}$ level unless otherwise noted.

\section{Results and Discussion}

While calix[4]arenes have four conformations: a cone. a partial cone. a 1.2-altemate. and a 1.3-altemate conformation ${ }^{1}$ tetrahomodioxacalix[4]arene can adopt five conformations with two different 1,2-alternate conformations: C-1.2alternate and $\mathrm{COC}$-1.2-alternate as shown in figure $1 .{ }^{13}$ For all structures. more than one representative of each conformation were found to be energy minima because of the large degree of freedom introduced by two dimethyleneoxa linkages in the macrocycle. Also. the orientation of the hydroxyl groups can vary. For each conformation. only the representative with the lowest energy at the corresponding
Table 1. Calculated relative energies (in $\mathrm{kcal} / \mathrm{mol}$ ) for 1 are listed at

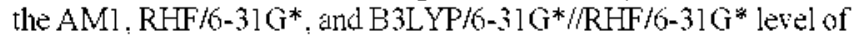
theory. Dipole moments (in Debye) at the RHF/6-31G* level are listed

\begin{tabular}{lrrcc}
\hline & AMI & $\begin{array}{c}\text { RHF/6- } \\
31 \mathrm{G}^{*}\end{array}$ & $\begin{array}{c}\mathrm{B} 3 \mathrm{LYP} / 6-31 \mathrm{G}^{*} \\
\text { /RHF/6-31G }\end{array}$ & $\begin{array}{c}\text { Dipole } \\
\text { moment }\end{array}$ \\
\hline Cone & 0.00 & 0.00 & 0.00 & 2.93 \\
C-1,2-altemate & 2.05 & 2.31 & 3.22 & 0.00 \\
Partial cone & 5.44 & 6.99 & 10.77 & 4.57 \\
l,3-altenate & 7.82 & 9.50 & 12.71 & 0.00 \\
COC-1,2-altenate & 10.92 & 17.84 & 20.64 & 0.00 \\
\hline
\end{tabular}

level of theory is listed and discussed below.

Conformational features of tetrahomodioxacalix[4]arene (1). The compound 1 is the simplest form of tetrahomodioxacalix [4]arene, yet no experimental structure has been reported due to its synthetic difficulty. For each conformation. AMl and RHF/6-31G* optimized structures are similar in shape and only RHF optimized geometries are shown in Figure 2. The relative energies and dipole moments are summarized in Table 1 . The theoretically predicted order of stability for 1 are cone $>$ C-1.2-alternate > partial cone $>$ 1.3 -alternate $>\mathrm{COC}$-1.2-alternate and this order is maintained at all levels of theory applied in this report. The stability order for tetrahomodioxacalix[4]arene is somewhat different from that for calix[4]arenes. where the stability order is cone $>$ partial cone $>1.2$-alternate $>1,3$-alternate. . $^{26-2 ?}$ As shown in Figure 2(a). the cone adopts the orientation that allows the formation of a cyclic array of intramolecular hydrogen bonds in the cavity. The high stability of the cone conformation is rationalized by the intramolecular lydrogen bonding array which links both phenolic and ether groups. Hy'drogen bonds are displayed in dashed lines at the top view of each structure in Figure 2. Four phenolic groups in a macrocycle of 1a act simultaneously as donor and acceptor to form four hydrogen bonds with $\mathrm{H}$ bond distance of $1.90 \mathrm{~A}$ or $2.30 \mathrm{~A}$. Also the two ether links. which give the molecule high flexibility are oriented to allow the ether oxygen atoms close to the phenolic proton giving two extra hy'drogen bonds with $\mathrm{H}$ bond distance of $1.98 \mathrm{~A}$. Thus. the shape of the cone is distorted by the formation of a cyclic hydrogen bonding array connecting four phenolic oxygen atoms and ether oxygens. resulting two bifurcated hydrogen bonds.

The second lowest energy-minima structure for 1 is found to be C-1.2-alternate. 1b. As shown in Figure 2(b). the distorted geometry due to $-\mathrm{CH}_{2} \mathrm{OCH}_{2}$ - linkages are reserved to allow hydrogen bonds between phenolic proton and the ether oxygen. but the cyclic hydrogen bonding array linking four phenolic groups is no longer available in the C-1.2alternate. The total number of hydrogen bonds is four in $\mathbf{~} \mathbf{b}$ instead of six in $1 \mathrm{a}$ with $\mathrm{H}$ bond distance of $1.90 \mathrm{~A}$. There is a two-fold axis of symmetry in $\mathbf{1 b}$ and the dipole moment is calculated to be zero. Each phenol ring carries a dipole along the $\mathrm{C}-\mathrm{O}$ bond axis pointing toward the aryl carbon atom. Accordingly. each set of adjacent phenol rings has an inherent propensity to adopt anti rather than syn orientation. 


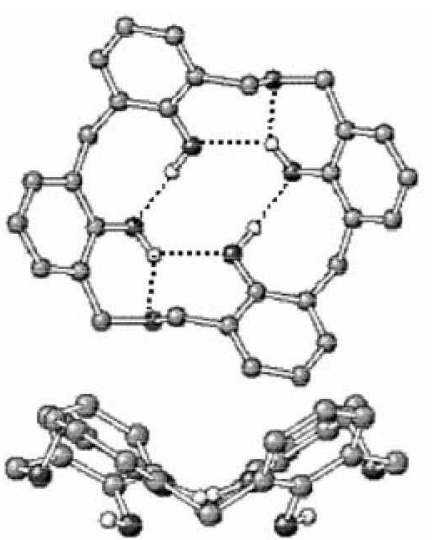

(a) cone

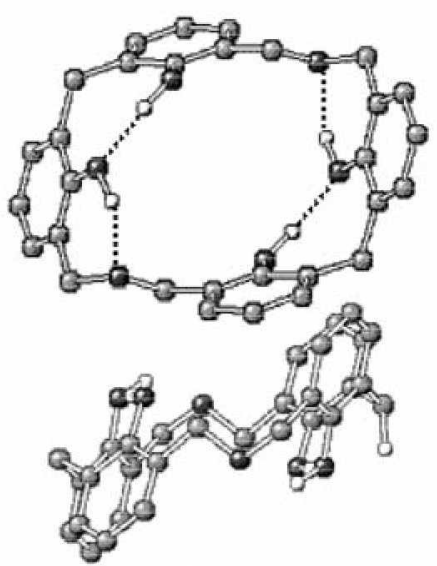

(b) C-1,2-alternate

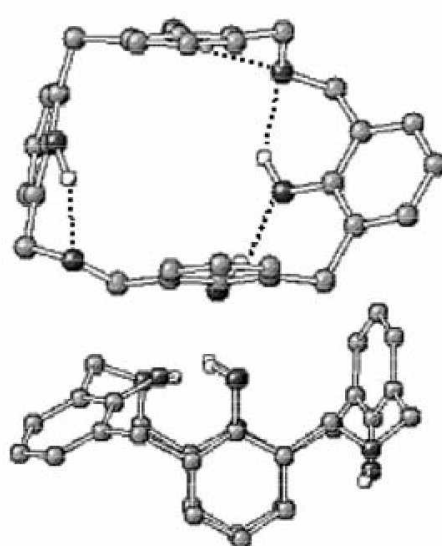

(c) partial cone

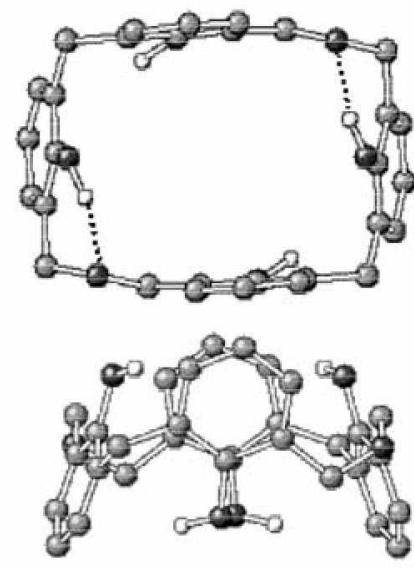

(d) 1,3-alternate

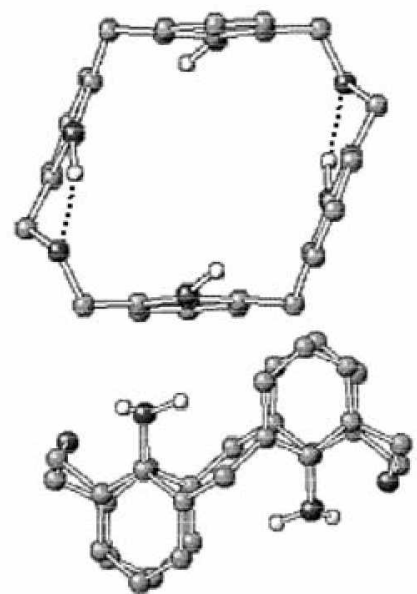

(e) COC-1,2-alternate

Figure 2. RHF/6-31G* optimized geometries of tetrahomodioxacalix [4]arenes (1): (a) cone, (b) C-1,2-altemate, (c) partial cone, (d) 1,3alternate, and (e) COC-1,2-alternate are shown. For each structure, top and side views are provided. Hydrogen bonds are shown in dashed lines at the top view. Oxygen atom is displayed in darker shade. Hydrogen atoms are omitted for clarity except the hydroxyl hydrogens.

In $1 \mathrm{~b}$. a set of phenol rings facing each other are parallel. but each set of adjacent phenol ring is almost orthogonal to each other. This shape is characterized to maximize the number of $\mathrm{H}$ bonds and to minimize the electrostatic repulsion. resulting $3.22 \mathrm{kcal} / \mathrm{mol}$ higher in energy for $1 \mathrm{~b}$ than that for 1a. The shape of the partial cone conformation. $1 \mathrm{c}$ is found to be $10.77 \mathrm{kcal} / \mathrm{mol}$ higher in energy than that for $1 \mathrm{a}$ and the shape is shown in Figure 2(c). Although there are four hydrogen bonds: the three between phenolic protons and the ether oxygens $(2.05 \mathrm{~A})$ and the one between two phenol groups $(1.95 \mathrm{~A})$. unavoidable electrostatic repulsions to maximize $\mathrm{H}$ bonds result high energy and large dipole moment. In the case of calix|4|arene. 1.3-alternate is the least stable conformation due to the lack of $\mathrm{H}$ bonds. On the other hand. in the case of tetrahomodioxacalix|4larene. two $\mathrm{H}$ bonds are found between the phenolic protons and the ether oxygens (1.98 A) in 1d. Here. each adjacent phenol ring is anti. which benefits the most from the electrostatic effect. The least stable conformation for 1 is found to be COC-1.2-alternate. 1e. The optimized geometry for 1e still forms two $\mathrm{H}$ bonds between phenolic protons and ether oxygens $(1.96 \mathrm{~A})$. resulting two phenol rings connected by $-\mathrm{CH}_{2} \mathrm{OCH} \mathrm{H}_{2}$-groups in close contact. As shown in figure $2 \mathrm{e}$. the angle between two planes associated with phenolic rings on each side of ether linkage is $\sim 70^{\circ}$. Electrostatic repulsions between adjacent phenol rings attribute to the high energy for $1 \mathrm{e}$.

Conformational features of tetrahomodioxa $p$ - $t$-butylcalix[4]arene (2) The compound 2 was first synthesized by Gutsche et $\mathrm{al}^{8 \mathrm{~b}}$ and it was concluded that 2 adopts a flattened cone conformation based on the temperature dependent ${ }^{1} \mathrm{H}$ NMR measurements. ${ }^{8 c}$ Recently, the crystal structure for $\mathbf{2}$ was reported to adopt a distorted cone. ${ }^{11}$ The RHF optimized structures for 2 are shown in Figure 3. For these different energy minima structures. the calculated thenmodynamic stabilities are listed in Table 2 . The theoretically predicted order of stability for $\mathbf{2}$ is in accordance with that for $\mathbf{1}$ that the cone is optimized to be most stable. As shown in Figure 3. the cavity shape for $2 a$ is very similar to that for 1 a in Figure 2. The cyclic array of the phenolic hydrogen bondings which link both phenolic and ether groups is critical enough to distort the macrocyclic ring of $2 \mathrm{a}$. Also the 


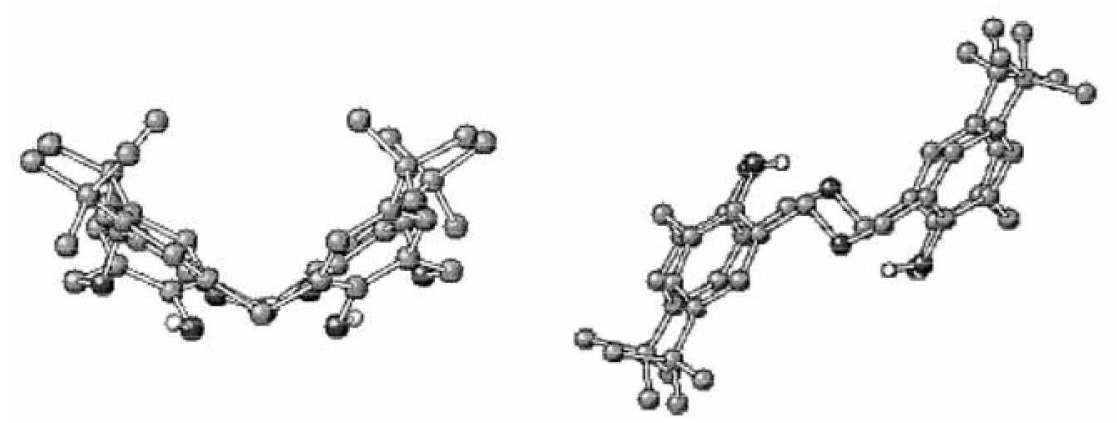

(a) cone (b) C-1,2-alternate

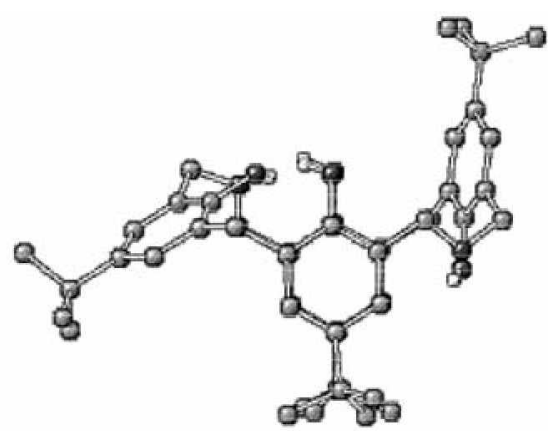

(c) partial cone

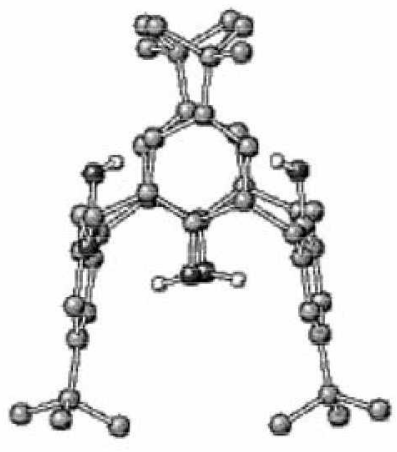

(d) 1,3-alternate

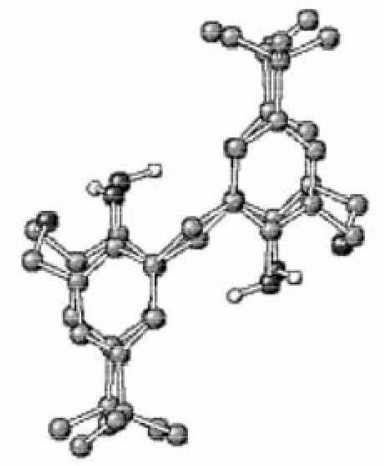

(e) COC-1,2-alternate

Figure 3. RHF/6-3IG* optimized geometries of tetrahomodioxa p-f-butylcalix[4]arenes (2): (a) cone, (b) C-1,2-altemate, (c) partial cone, (d) 1,3-altennate, and (e) COC-1,2-altennate are shown. Oxygen atom is displayed in darker shade. Hydrogen atoms are omitted for clarity except the hydroxyl hydrogens.

Table 2. Calculated relative entergies (in $\mathrm{kcal} / \mathrm{m}$ ol) for 2 are listed at the AM1, RHF/6-31G*, and B 3LYP/6-31G*/RHF/6-31G* level of theory. Dipole moments (in Debye) at the RHF/6-31G* level are listed

\begin{tabular}{lrrcc}
\hline & AMI & $\begin{array}{c}\mathrm{RHF} / 6- \\
31 \mathrm{G}^{*}\end{array}$ & $\begin{array}{c}\mathrm{B} 3 \mathrm{LYP} / 6-31 \mathrm{G}^{*} \\
/ / \mathrm{RHF} / 6-31 \mathrm{G}^{*}\end{array}$ & $\begin{array}{c}\text { Dipole } \\
\text { moment }\end{array}$ \\
\hline Cone & 0.00 & 0.00 & 0.00 & 3.36 \\
C-1,2-altemate & 1.83 & 2.02 & 3.11 & 0.00 \\
Partial cone & 5.22 & 8.19 & 11.87 & 4.81 \\
1,3-altemate & 8.14 & 9.37 & 12.85 & 0.00 \\
COC-1,2-altemate & 10.99 & 17.82 & 20.74 & 0.00 \\
\hline
\end{tabular}

$\mathrm{H}$ bond distances found in $2 \mathrm{a}$ are almost the same as the ones in la suggesting the para $t$-butyl groups do not disturb the shape. Masci et al. reported two different crystal structures for $2 \mathrm{a}$ : one in $\mathrm{CH}_{3} \mathrm{CN}$ solvent and the other in $\mathrm{C}_{5} \mathrm{H}_{3} \mathrm{~N}$ and they differ in ether linkage conformations and intramolecular H-bonding pattem. " We located both of these cone conformations at both $\mathrm{AMl}$ and $\mathrm{RHF} / 6-31 \mathrm{G}^{*}$ level. The lowest energy conformation. 2a. was discovered to be in accordance with the X-ray structure in $\mathrm{CH}_{3} \mathrm{CN}$ solvent. which is $2.6 \mathrm{kcal} / \mathrm{mol}$ lower in energy than the other that resembles the X-ray structure in $\mathrm{C}_{5} \mathrm{H}_{3} \mathrm{~N}$. Soon after the same authors reported a different crystal structure for $\mathbf{2}$ in different solvent șistem. which shows only slight conformational changes in the ether linkages. " Compared to 1 , the $p$ - $t$-butyl substituents in $\mathbf{2}$ do not affect the overall shape but increase the polarity of the molecule.

The C-1.2-alternate, 2b. is only $3.11 \mathrm{kcal} / \mathrm{mol}$ higher in energy than that for 2a. As shown in figure 3, the confomational features of $\mathbf{2 b}$ are very similar to those of $\mathbf{1 b}$ with four intramolecular $\mathrm{H}$ bonds in the macrocyclic ring. Also. the effect of the $p$ - $t$-butyl substituents is not observed in the overall shape. The partial cone $2 \mathrm{c}$. in Figure 3 is 11.87 $\mathrm{kcal} / \mathrm{mol}$ higher in energy than that for $2 \mathrm{a}$ and only $1 \mathrm{kcal} /$ mol lower than that for $\mathbf{2 d}$. The $p$ - $t$-butyl groups in $\mathbf{2 c}$ influence to the dipole of the molecule to be 4.81 debye with no geometrical change compared to $1 c$. $2 \mathrm{e}$ is the least stable structure. As for the case of $1 \mathrm{e}$, due to the electrostatic repulsions between adjacent phenol rings. this COC-1.2alternate is not likely to be the uncomplexed ligand structure in solution.

Conformational features of tetrahomodioxa $p$-phenylcalix [4]arene (3). It is only recently that the facile synthetic method ${ }^{14}$ was reported for 3 and soon after, the first crystal structure of complexed tetrahomodioxa $p$-phenylcalix $[4]$ arene was reported to be a cone conformation. ${ }^{18}$ The $\mathrm{RHF} / 6-$ 31G* optimized structures for 3 are shown in Figure 4 and the energetics are summarized in Table 3 . The theoretically predicted order of stability with $p$-phenyl substituents of 3 is remained the same compared to the ones for 1 and 2 . In the most stable conformation, 3a. $\mathrm{H}$ bonding pattems and $\mathrm{H}$ bond distances are reserved compared to 1 a or $2 a$. The cone. $3 a$ is $3 \mathrm{kcal} / \mathrm{mol}$ lower in energy than that for $3 \mathrm{~b}$. The energy of the most unstable structure. $3 \mathrm{e}$. is $18.77 \mathrm{kcal} / \mathrm{mol}$ higher 


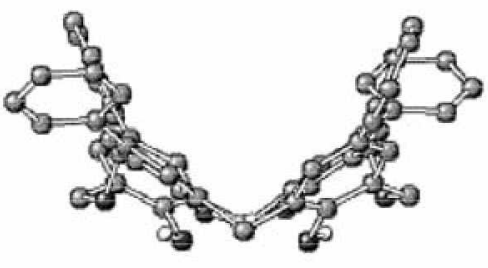

(a) cone

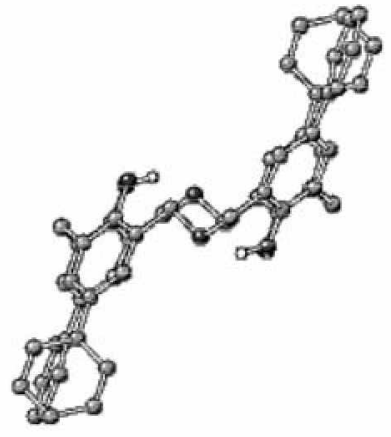

(b) C-1,2-alternate

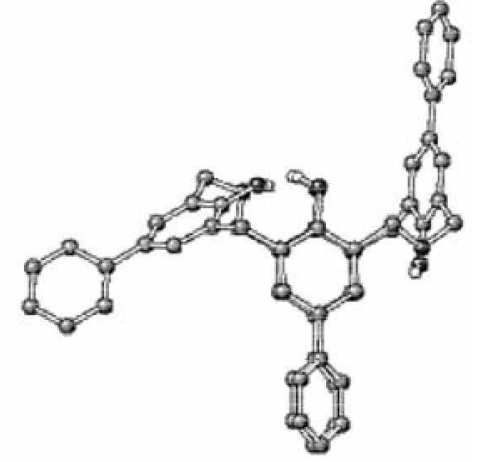

(c) partial cone

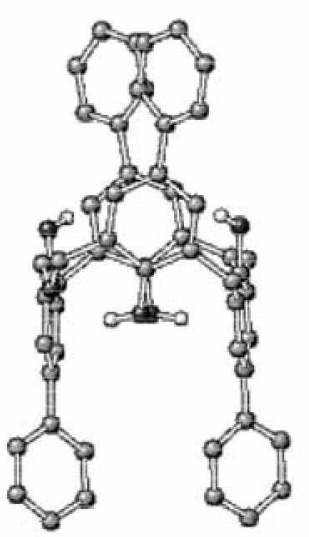

(d) 1,3-alternate

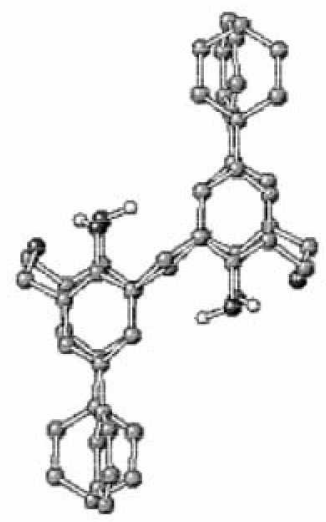

(e) COC-1,2-alternate

Figure 4. RHF/6-31G* optmized gemetnes of tetrahomodioxa p-phenylcalix[4]arenes (3): (a) cone, (b) C-1,2-altenate, (c) partial cone, (d) 1,3-altemate, and (e) COC-1,2-altemate are shown. Oxygen atom is displayed in darker shade. Hydrogen atoms are omitted for clarity except the hydroxyl hydrogens.

Table 3. Calculated relative energies (in $\mathrm{kcal} / \mathrm{mol}$ ) for 3 are listed at the AMl, RHF/6-31G*, and B3LYP/6-3IG*//RHF/6-31G* level of theory. Dipole moments (in Debve) at the RHF/6-31 $G^{*}$ level are listed.

\begin{tabular}{lrrcc}
\hline & AMl & $\begin{array}{c}\mathrm{RHF} / \\
6-31 \mathrm{G}^{*}\end{array}$ & $\begin{array}{c}\mathrm{B} 3 \mathrm{LYP} / 6-31 \mathrm{G}^{*} \\
\text { /RHF/6-31G* }\end{array}$ & $\begin{array}{c}\text { Dipole } \\
\text { moment }\end{array}$ \\
\hline Cone & 0.00 & 0.00 & 0.00 & 2.77 \\
C-1,2-altemate & 2.05 & 2.30 & 2.97 & 0.00 \\
Partial cone & 5.53 & 6.76 & 10.86 & 4.71 \\
1,3-altemate & 8.39 & 9.28 & 12.60 & 0.00 \\
COC-1,2-altemate & 12.09 & 16.07 & 18.77 & 0.00 \\
\hline
\end{tabular}

than that for 3a. It is noted that $p$-phenyl substituents are twisted from the parent phenol rings with the dihedral angle between phenolic plane and $p$-phenyl plane to be $45^{\circ}$ in all structures. This is rationalized to avoid the overlap between phenyl hydrogens from adjacent aryl rings. The intramolecular hydrogen bonding pattems still play the most important role to determine the conformations of 3 .

\section{Conclusion}

In the present paper. we report the first theoretical study on the conformational features of parent tetrahomodioxacalix [4]arenes with three different para substituents using semiempirical and quantum mechanical theory in a gas phase. The molecular dynamic simulations were used for conformational analy'sis to locate initial structures for AMl geometry optimization for each compound. Then further optimization at the $\mathrm{RHF} / 6-31 \mathrm{G}^{*}$ level was performed followed by the single point energy calculation at the B3LYP/6-3iG* using RHF optimized geometry for each minima structure. Different from calix[4/arenes. tetrahomodioxacalix/4|arenes can adopt five different conformations and the stability sequence is predicted to be cone $>\mathrm{C}-1.2-$ alternate $>$ partial cone $>1.3$-alternate $>$ COC-1.2-alternate regardless of the para substituents in the phenolic ring. The cone as being most stable is in agreement with the experimental observations by X-ray and NMR. The conformation of the cone is calculated to adopt the distorted and flattened cavity shape with cyclic array of phenolic $\mathrm{H}$ bonds and the bifurcated $\mathrm{H}$ bonds linking phenolic proton and ether oxygens as observed by X-ray structure. The substitution of metlyylene with dimethyleneoxa bridges increases the size of the annulus of the molecule. its conformational mobility and the number of hydrogen bonding pattems. The substituent effect on para position of the phenolic ring is not observed to affect the overall shape and themal stability order. The conformational analyses show that the most important factor 
to determine the geometry is the intramolecular hydrogen bonding pattem displayed by the phenolic groups and ether linkages in the cavity.

Acknowledgment. This research was supported by the Sookmyung Women's University Research Grant. 2003.

\section{References}

1. (a) Gutsche, C. D. Galixanemes. Roval Society of Chemistry: Cambridge. 1989. (b) Calixarmes: A liersatile Class of Macrocyclic Compounds: Vicens. J. Böhmer. V. Eds.: Kluwer: Dordrecht. 1991 .

2. (a) Gutsche. C. D. Calixarenes. Roval Society of Chemistry: Cambridge, 1989, Ch. 2. (b) Gutsche. C. D. Calixaremes Revisited. Roval Society of Cheminstry: Cambridge. 1998. Ch. 2. (d) Catixanales. Asfàri. Z.. Böhmer. V. Harrowfield, J. Vicens. J.. Eds.: Kluwer Academic Publishers: Dordrecht. The Netherlands. 2001. Ch. 12 and references therein.

3. Harrowtield. J. M.: Ogden. M. I.: White. A. H. J. Chent. Soc., Dalton Trans. 1991, 979

4. Asfari. Z: Harrowfield J. M: Ogden. M. I.: Vicens. T.: White, A. H. Angew. Chem. Int Ed. Engl. 1991. 30,854.

5. Marcos. P. M.: Ascenso. J. R.: Lamartine. R.: Pereira. J. L. C. Tetrahedron 1997, 53.11791.

6. Felix. S.: Ascenso. J. R.: Lamartine. R.: Pereira. J. L. C. Sin. Commin. 1998. 28.1793.

7. Bavoux C.: Vocanson. F.: Perrin. M: Lamartine, R J. Incl. Phenom. Hol. Recogn. Chem. 1995, 22.119.

8. (a) Gutsche. C. D: Dhawan, B.; No, K. H.: Muthukrishman, R. J. Am. Chem. Soc. 1981. 103. 3782. (b) Dhawan. B.: Gutsche. C. D. J. Org. Chem. 1983. 48. 1536. (c) Gutsche. C. D.: Bauer. L. J. J. Am. Chen. Soc. 1985. 107.6059.

9. (a) Masci, B.: Saccheo. S. Tetrahetron 1993. 49, 10739. (b) De Iasi. G.; Masci. B. Tetrahedron Lett 1993, 3f, 6635. (c) Masci, B. Tetrahedron 1995. 51. 5459

10. Masci. B.: Finelli. M.: Varrone. M. Chem. Etur J. 1998. 4. 2018.

11. Thuèry. P.: Nierlich. M.: Vicens. J.: Masci. B.: Takemura. H. Eut J. Inorg. Chem. 2001. 637.

12. Thuer. P.: Nierlich, M.: Vicens, J.: Masci. B. Acta Const. 2001. C57,70.

13. No, K.: Lee, J. H.: Yang. S. H.: Kim, M. J; Kim. J. S. J. Org. Chent 2002.67.3165.
14. No. K. H. Bull. Korean Chem. Soc. 1999. 20, 33

15. No. K. H.: Park. Y. T.: Choi. E. J. Bull. Korean Chent. Soc. 1999. 20.905 .

16. Masci. B. J. Org. Chent 2001. 66. 1497

17. No. K.: Kim, J. S.; Shon, O. J.; Yang. S. H.: Suh, I. H: Kim, J. G.; Bartsch, R. A.; Kim. J. Y. J. Org. Chem. 2001, 66, 5976.

18. Masci. B., Gabrielli, M.: Mortera. S. L.: Nierlich, M.: Thuèry. P Pollhedron 2002. 21. 1125 .

19. No. K.: Chung. H. J.: Yu. H. T.: Yang. S. H.: Noh. K. H.: Thuery. P.: Vicens. T.: Kim. T. S. J. Incl Phenon. Macro Chem. 2003. t6. 97.

20. No. K.; Bok, J. H.; Suh, I. H; Kang, S. O; Ko, J.; Nam. K. C.; Kim. J. S. J. Org. Chem. 2004. 69,6938.

21. Case. D. A.: Pearlmant. D. A.: Caldwell. J. W. ef al. AMBER 7: University of California. San Francisco. 2002.

22. Berendsent. H. J. C.: Postma. T. P. M.: van Gunsteren. W. F.: DiNola A.: Haak: J. R. J. Chem. Phys. 1984, 81,3684.

23. Dewar, M.; Thiel. W. J. Am Chem. Soc, 1977,99 , 499 ; Dewar. M.: Zoebisch, E. G. Healy, E. F. $J$. Am. Chem Soc 1985. 107. 3902 .

24. Frisch. M. I.: Truchs. G. W.: Schlegel. H. B.: Scuseria. G. E.: Robb. M. A.: Cheeseman. J. R.: Zakrzewski. V. G.: Montgomery. Jr.. J. A.: Stratmann. R. E.; Burant. J. C.: Dapprich, S.; Millam. J. M; Daniels, A. D; Kudin. K. N.; Strain. M. C.; Farkas. O: Tomasi, J.: Barone. V.: Cossi, M.: Cammi, R.: Mennucci, B.: Pomelli. C.: Adamo. C.: Clifford. S.: Ochterski. T.: Petersson. G A.: Avala. P. Y.: Cui. Q.: Morohuma. K.: Malick. D. K.: Rabuck. A. D.: Raghavachari. K.: Foresman. J. B.: Cioslowshi. T.: Ottiz. J. V.: Baboul, A. G.: Stefanov, B. B.: Liu, G.; Liashenko, A.; Piskorz. P.: Komaromi. I.: Gomperts. R.: Martin. R. L.: Fox. D. J.: Keith. T.: Al-Laham. M. A.; Peng, C. Y: Nanayakkara. A.: Gonzalez. C. Challacombe. M. Gill, P. M. W: Johnson. B Chen. W: Wong. M. W. Andres. T. L.: Gonzalez. C.: HeadGordon. M.: Replogle. E. S.: Pople. T. A. Ganssian 98. Revision A.7: Gaussian. Inc.: Pittsburgh. PA. 1998.

25. Becke. A. D. J. Chem. Phus. 1993. 98.5648

26. Grootenhuis, P. D; Kollman, P. A; Groenen, L. C.; Reinhoudt, D N.; van Hummel. G. J.: Ugozzoli, F; Andreetti. G. D. l. Am. Chent Soc. 1990. 112.4165.

27. Fisher. S.: Grootenhuis. P. D. J.: Groenent. L. C.: $\operatorname{van}$ Hoorn. W. P.: van Veggel. F. C. J. M.: Reinhoudt. D. N.: Karplus. M. J. Ant. Chem. Soc. 1995. $117,1610$.

28. van Hoorn. W. P.: Briels. W. J.: van Duynhoven. J. P. M.; van Veggel. F. C. J. M.; Reinhoudt. D. N. J. Org. Chem. 1998, 63. 1299. 